Vladimir Miletić

Centar za nove tehnologije Viminacium d.o.o.

miletic.vladimir@gmail.com

Jelena Miletić

Centar za nove tehnologije Viminacium d.o.o.

UDK 902.3:550.8(497.11)"2006";

904:725.182"653"(497.11)

izvorni naučni članak

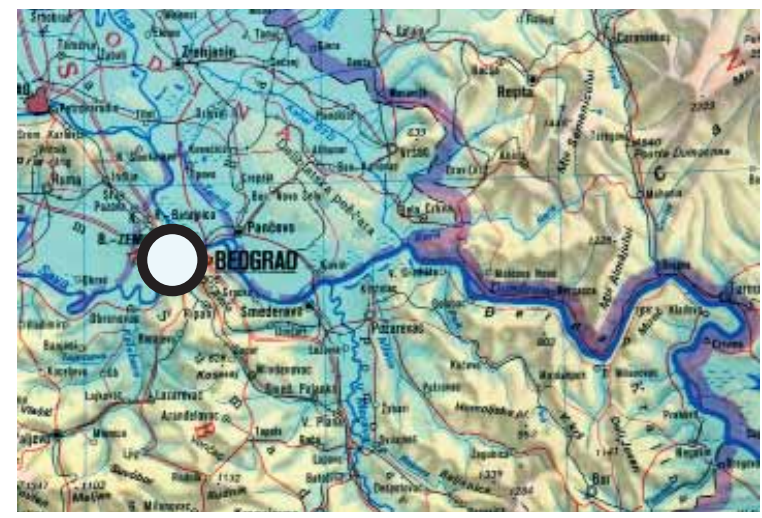

Beograd, Srbija

LAT $44^{\circ} 49^{\prime} 25^{\prime \prime}$ / LONG 20²6’ 60"

\title{
PREGLED GEORADARSKIH ISTRAŽIVANJA GORNJEG I DONJEG GRADA BEOGRADSKE TVRĐAVE
}

\begin{abstract}
APSTRAKT
Na prostoru Gornjeg i Donjeg grada Beogradske Tvrđave, tokom 2006.godine, izvršena su kompleksna geofizička istraživanja za potrebe zaštite podzemnih arheoloških objekata i njihove eventualne sanacije i revitalizacije. Izvedena istraživanja ukazala su na postojanje velikog broja objekata ispod površine tla kao i na postojanje šupljina u konstrukciji objekata, gde se kao posledica može očekivati sleganje tla pod uticajem opterećenja.
\end{abstract}

\section{KLJUČNe REČI: GEOFIZIKA, ISTRAŽIVANJA, GPR, BEOGRAdSKA TVRĐAVA}

\section{UVOD}

Na prostoru Gornjeg i Donjeg grada Beogradske Tvrđave, tokom 2006.godine, izvršena su kompleksna geofizička istraživanja za potrebe zaštite podzemnih arheoloških objekata i njihove eventualne sanacije i revitalizacije. U ovim istraživanjima korišćene su različite geofizičke metode koje su prilagođene arheološkim istraživanjima, i koje zahtevaju visoku rezoluciju dobijenih podataka u bliskopovršinskom sloju terena, odnosno prikupljanje velikog broja podataka za kratko vreme. Razvojem novih geofizičkih metoda i računarske opreme koja omogućava obradu velike količine podataka (2D i 3D analize), omogućeni su uslovi za kompleksno geofizičko istraživanje čitavog prostora Gornjeg i Donjeg grada Beogradske Tvrđave, uz primenu najsavremenijih metoda. U istraživanja su inkorporirane i metode na osnovu kojih je izvršena seizmička mikrorejonizacija ovog prostora, analiza hidrokolektorskih formacija, kao i izrada digitalnog modela terena (DTM). U okviru primenjenih geofizičkih metoda posebno se izdvajaju elektromagnetske metode (georadar - GPR), koje su po svojoj prirodi potpuno nedestruktivne a pružaju daleko najvišu rezoluciju registrovanih podataka. Stoga je GPR i najzastupljenija metoda primenjena u ovim istraživanjima, te će njeni rezultati biti prikazani u ovom radu.

Kompleksna geofizička straživanja prostora Gornjeg i Donjeg grada Beogradske Tvrđave, su izvedena u cilju dobijanja celovite slike o stanju prostornih celina Gornjeg grada i Donjeg grada, tj. tačne pozicije podzemnih objekata, njihovog gabarita i strukture, kao i dobijanja podataka o 
postojanju podzemnih prostorija i uticaju potresa i podzemnih voda. Pored geofizičkih, korišćene su i savremene geodetske metode koje su omogućile precizno pozicioniranje rezultata istraživanja i dale dobru podlogu za njihov prikaz.

\section{METODOLOGIJA I USLOVI ISTRA- ŽIVANJA}

Metoda koja na osnovu dobijenih rezultata svakako predstavlja osnovu geofizičkih istraživanja na prostoru Beogradske tvrđave je georadarska metoda. Ova metoda predstavlja najrezolutniju geofizičku metodu i nakon smetnji kojima su bile opterećene druge geofizičke metode, georadarska metoda je korišćena na čitavom istražnom prostoru. Naime, ispostavilo se da prisustvo podzemnih instalacija, korenja stabala i velike količine rasutog materijala u površinskim slojevima ne predstavlja ozbiljnu smetnju za primenu georadarske metode na ovom prostoru, te je primenjena na čitavoj istražnoj površini. Akvizicija podataka georadarskom metodom je izvršena na ukupnoj površini od 13,6 ha, i to uglavnom u okvirima istražnih polja, dok je na lokacijama gde je ovakvo snimanje bilo onemogućeno akvizicija vršena duž pojedinačnih georadarskih profila. Ukupna površina istražena georadarskom metodom prikazana je u prilogu 1 .

Georadarska metoda (GPR) je primenjena korišćenjem švedske aparature RAMAC CUII i antene od $250 \mathrm{MHz}$ sa vremenskim opsegom od 92 ns (dubinski zahvat od oko 4,4 m). Prilikom akvizicije podataka, horizontalna rezolucija iznosila je podatak na svakih $1 \mathrm{~cm}$ georadarskog profila, dok je vertikalna rezolucija iznosila 1024 podatka po jednoj trasi. Za vreme snimanja antena je pokretana ručno i ostvarivala je direktan kontakt sa tlom. Georadarska istraživanja su se odvijala u okvirima kvadratne mreže (istražna polja dimenzija 20x20m). U okviru svakog polja registrovani su paralelni profili na $0.5 \mathrm{~m}$ međusobnog rastojanja. Na ovaj način, već od dubine $25 \mathrm{~cm}$, postignuto je potpuno prekrivanje terena.

Obrada GPR podataka vršena je programskim paketom REFLEXW na način da su svi registrovani profili normalizovani i filtrirani pojedinačno, a zatim je za svako istražno polje generisan 3D model. Iz 3D modela izdvajani su horizontalni preseci za odabrane dubinske nivoe, koji se zatim uklapaju kao mozaik u elektromagnetske karte čitavog istražnog prostora.

\section{REZULTATI ISTRAŽIVANJA}

Rezultati georadarske prospekcije prikazani su dvojako: u vidu karata elektromagnetskih anomalija i u vidu pojedinačnih profila.

Karte elektromagnetskih anomalija predstavljaju horizontalne preseke, dobijene iz 3D modela, za odgovarajuće dubinske nivoe. U ovom radu su prikazani preseci za dubinski nivo od oko $100 \mathrm{~cm}$.

Radi bolje preglednosti karte elektromagnetskih anomalija su podeljene po svom položaju u tri grupe:

- jugozapadni deo Donjeg grada - prilog 2

- severoistočni deo Donjeg grada - prilog 3

- Gornji grad - prilog 4.

Za karte elektromagnetskih anomalija je za prikaz odabrana varijanta palete od crne do bele boje, jer iskustvo pokazuje da je ovakav prikaz najkontrastniji i veoma pogodan za interpretaciju. Razmatrajući dobijene karte elektromagnetskih anomalija, potrebno je naglasiti da nijanse crne boje predstavljaju relativno homogen prostor, dok nijanse bele boje predstavljaju nehomogenosti ispod površine tla, odnosno ukazuju na eventualno prisustvo podzemnih objekata. Ono što izdvaja podzemne arheološke objekte i podzemne instalacije od drugih nehomogenosti u tlu su pravilni geometrijski oblici, koji se mogu primetiti na priloženim kartama.

Posmatrajući različite dubinske nivoe, može se uočiti da je istražen prostor u jugozapadnom delu Donjeg grada, Gornjeg grada kao i Zapadnog podgrađa, ispunjen arheološkim sadržajem. To se najviše može primetiti na dubinama od $1 \mathrm{~m}$ do $2.25 \mathrm{~m}$. Što se tiče severoistočnog dela Donjeg grada, primećuje se da su nehomogenosti uglavnom koncentrisane u pojasu neposredno uz dunavsku padinu.

U prilozima 5, 6 i 7, dat je primer interpretacije rezultata dobijenih georadarskom prospekcijom. Na priloženim elektromagnetskim kartama vrlo jasno se mogu primetiti različiti objekti koji se nalaze u bliskopovršinskom sloju. Oni se relativno jednostavno izdvojaju od okolne sredine 
zahvaljujući dobrom kontrastu elektromagnetskih svojstava materijala od kojih su objekti izgrađeni i okolnog tla.

Obzirom na visoku preciznost pozicioniranja dobijenih podataka, na osnovu dobijenih rezultata se mogu vršiti upoređenja sa georeferenciranim kartama i planovima iz raznih perioda, što pruža velike mogućnosti u budućem sagledavanju ovog prostora i prepoznavanju nekih objekata. Jedan od primera ovakve komparacije prikazan je u prilogu 8 , gde se mogu uočiti poklapanja postojećih ostataka nekadašnjih objekata i objekata koji se mogu primetiti na planu iz 1790 . godine. Minimalna poziciona odstupanja koja se primećuju su posledica georeferenciranja starih planova Beogradske tvrđave i nesavršene opreme korišćene za pozicioniranje iz tog vremena.

Takođe, interesantno je i poređenje geofizičkih rezultata dobijenih geoelektričnim istraživanjima koja su vršena 1990. godine (Filozofski Fakultet Ljubljana, B. Mušič) i savremenih rezultata dobijenih GPR metodom (prilog 9). Ovaj primer ukazuje na apsolutno poklapanje podataka dobijenih u različito vreme i različitim geofizičkim metodama.

Geodetska snimanja terena koja su za svrhu imala izradu digitalnog modela terena, omogućila su i prikaz rezultata GPR istraživanja zajedno sa 3D modelom terena (prilog 11). Ovakav način prikaza može pomoći kod razmatranja dobijenih rezultata u širem prostornom kontekstu.

\section{ZAKLJUČNA RAZMATRANJA}

Izvedena istraživanja prostora Gornjeg i Donjeg grada Beogradske Tvrđave ukazala su na postojanje velikog broja objekata ispod površine tla na prostoru Donjeg Grada i Gornjeg Grada Beogradske Tvrđave. Neki od tih objekata su poznati, a neki nisu, ali ova istraživanja su svakako prilika da se njihovi gabariti precizno odrede i definišu u prostoru. Dobijeni rezultati GPR prospekcije omogućiće u narednom periodu različite analize koje će poslužiti za jednostavnije projektovanje daljih zaštitnih i arheoloških radova. Jedna od takvih analiza je i analiza koja je načinjena u svrhu detektovanja šupljina ispod površine tla (prilog 10). Na prostoru Donjeg Grada održavaju se manifestacije tokom letnjeg perioda, gde sleganje terena usled postojanja šupljina ili usled opte- rećenja sa površine, može dovesti do uništavanja arheoloških objekata ili ozleđivanja posetilaca. Stoga je pravovremena detekcija mesta koja su kritična po ovom pitanju od velikog značaja. U prilogu 10 prikazana je analiza eventualnog postojanja šupljina u konstrukciji objekata koji se nalaze ispod površine tla, gde se kao posledica može očekivati sleganje tla u bliskoj budućnosti. Ova mesta su izolovana na kartama (crvenom bojom u prilogu) i prezentovana službama koje će vrsiti sanaciju i zastitu.

\section{OVERVIEW OF GPR RESERCH IN THE AREA OF UPPER TOWN AND LOWER TOWN OF BELGRADE FORTRESS}

In the area of Upper Town and Lower Town on Belgrade Fortress, in 2006, complex geophysical research was carried out in the purpose of protection of underground archaeological structures and their eventual rehabilitation and revitalization. Research carried out showed the existence of a large number of objects beneath the surface of the soil as well as area where subsidence of soil by the influence of the load could be expected as a result of existence of a cavity in the construction of buildings.

KEY WORDS: GEOPHYSICAL, RESEARCH, GPR, BELGRADE FORTRESS 


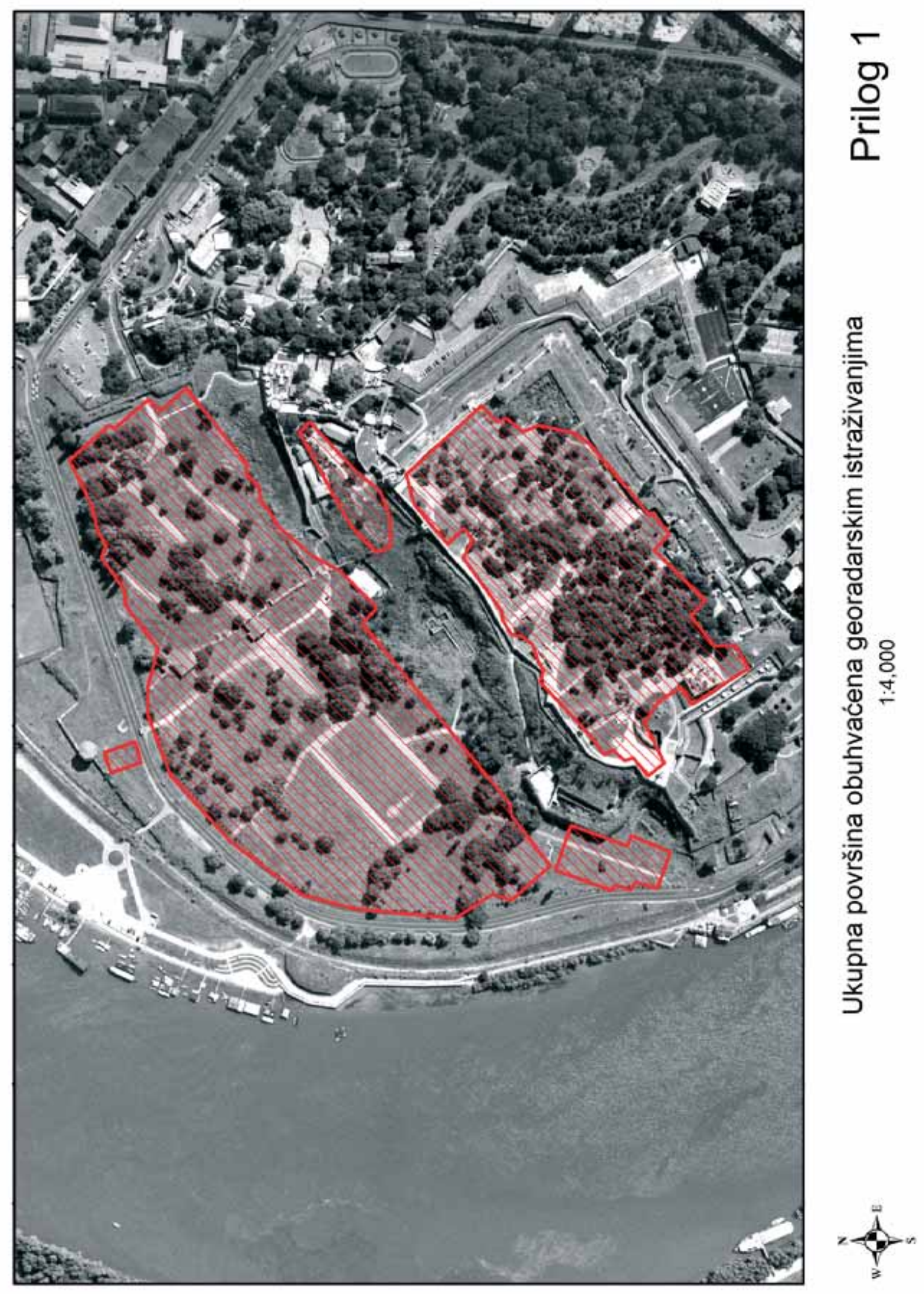




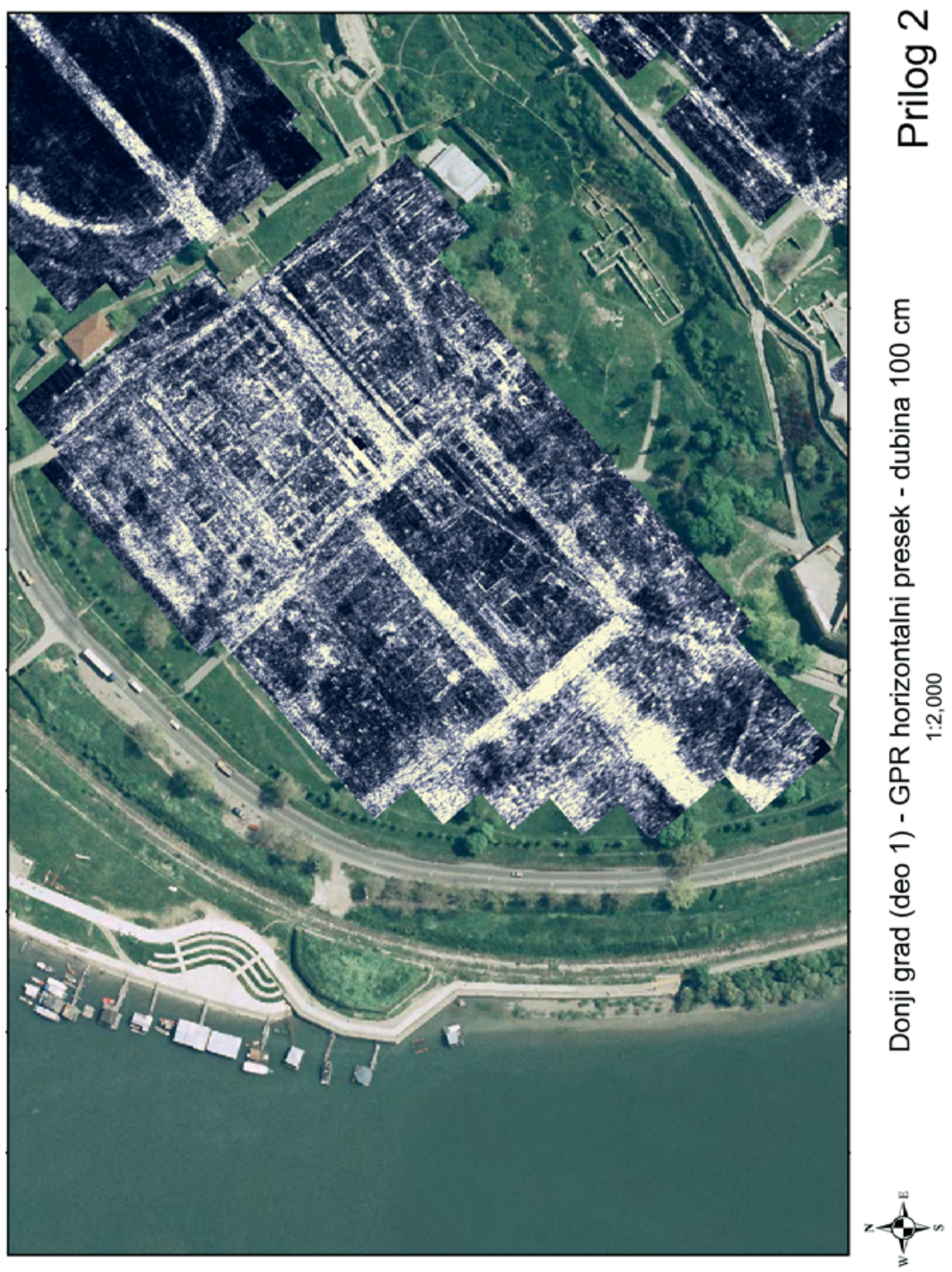




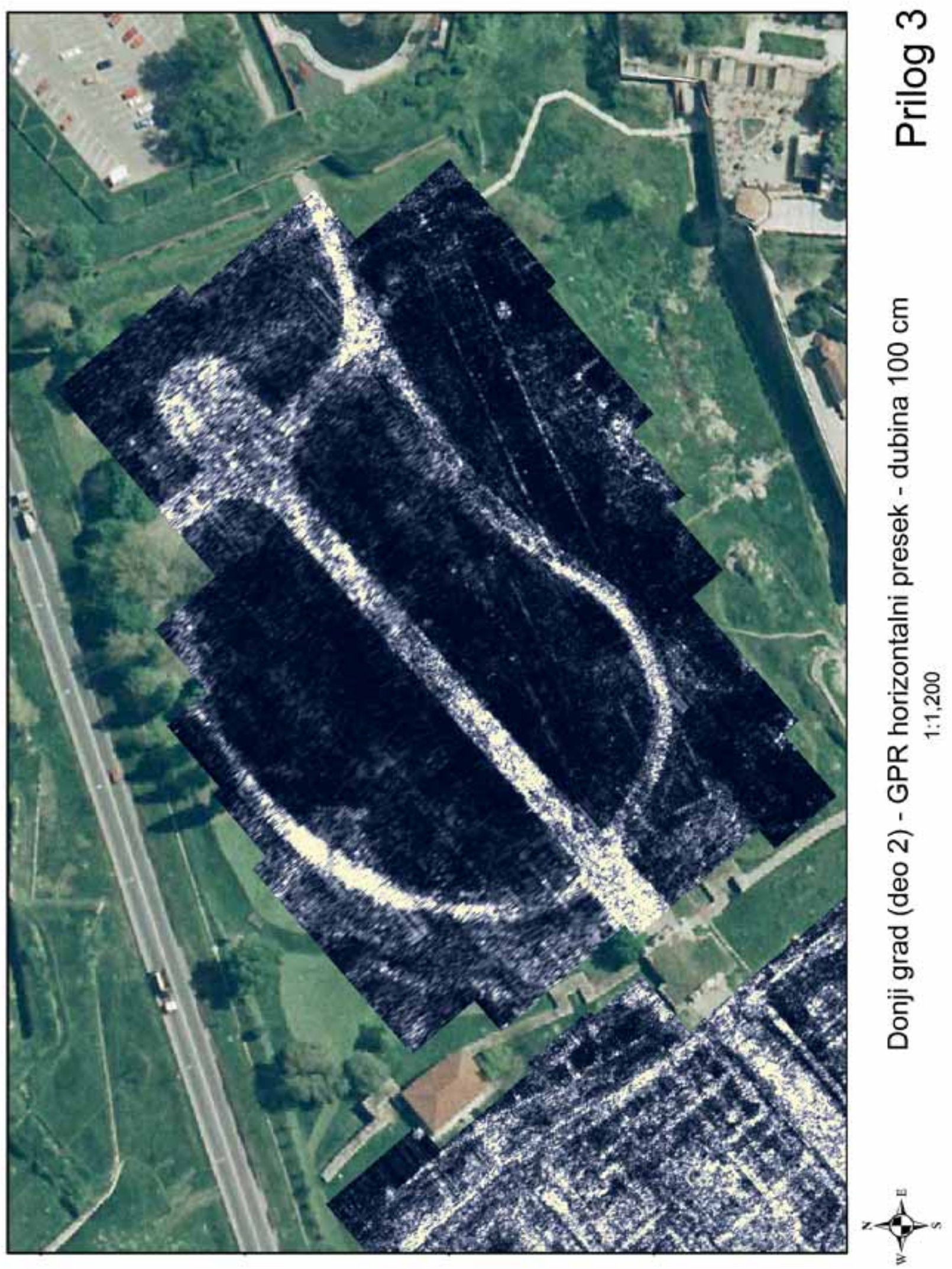




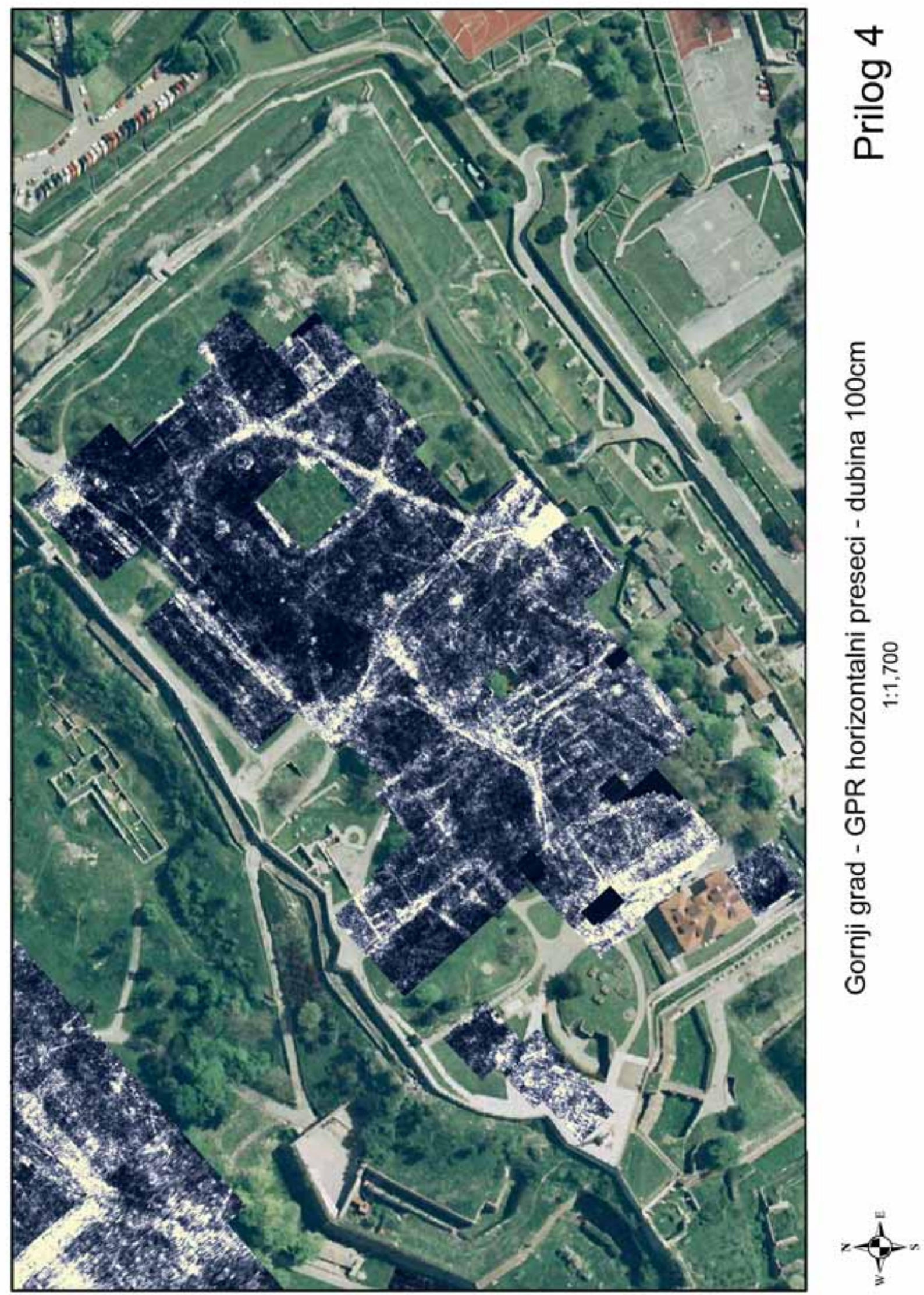




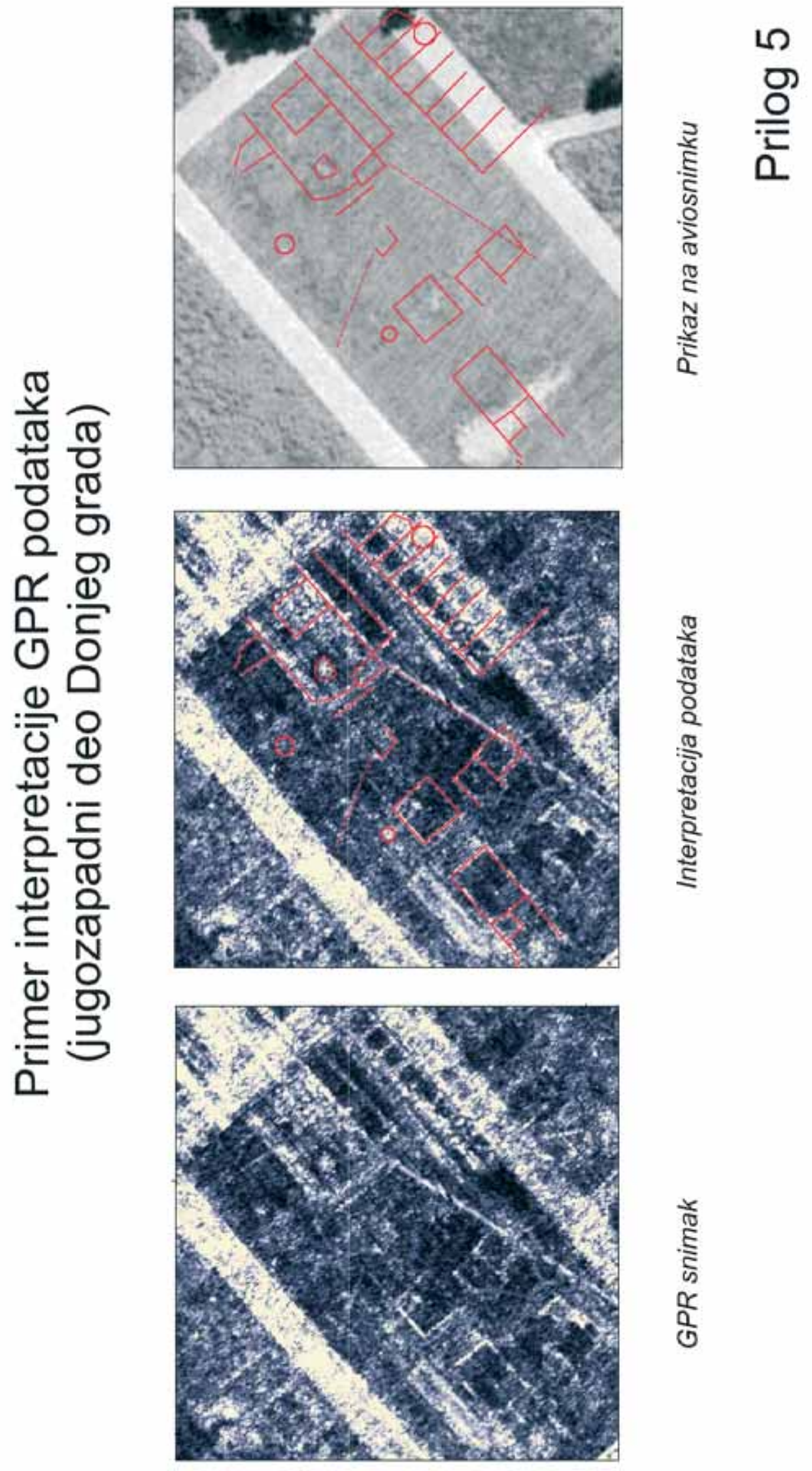




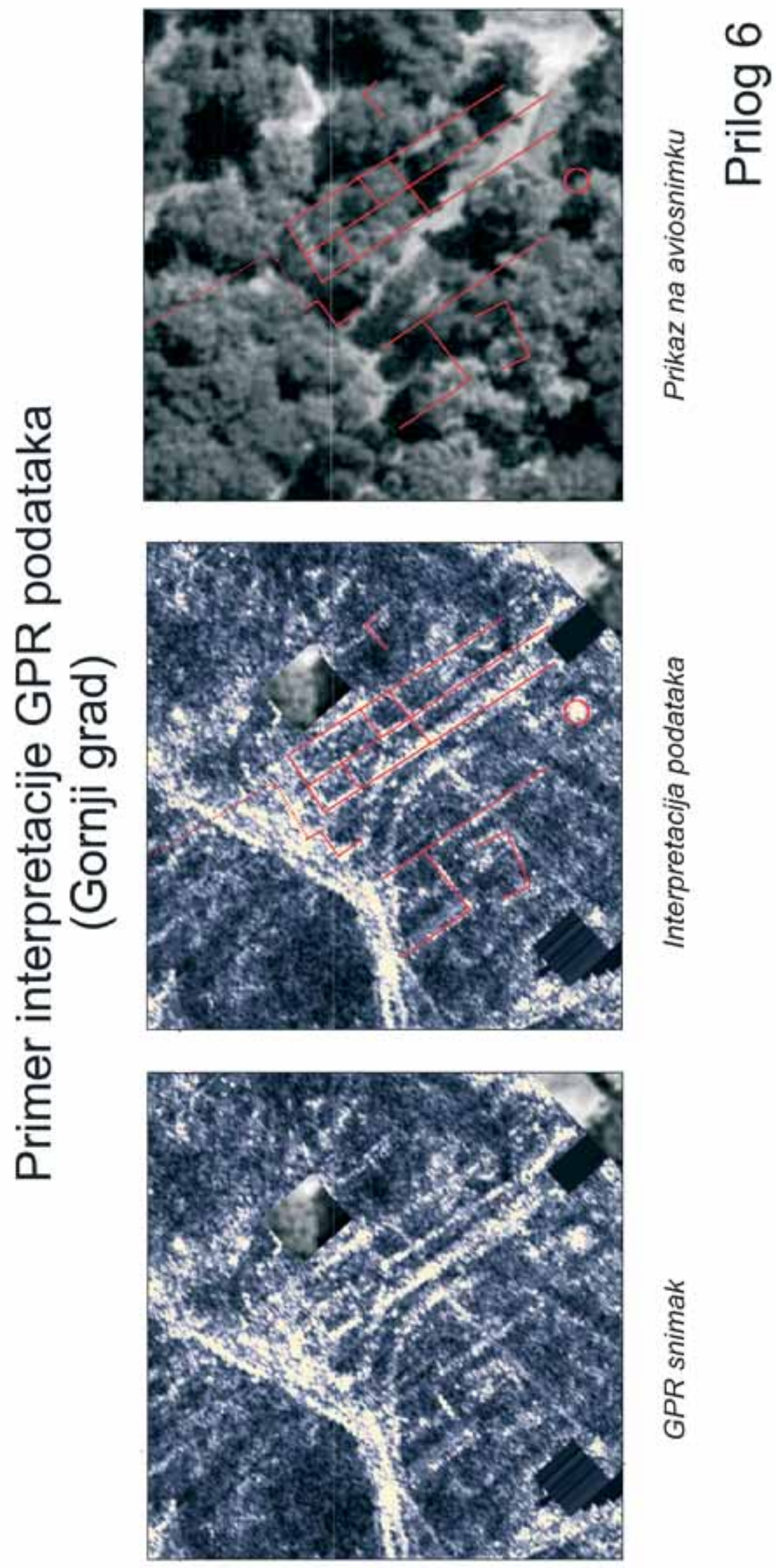




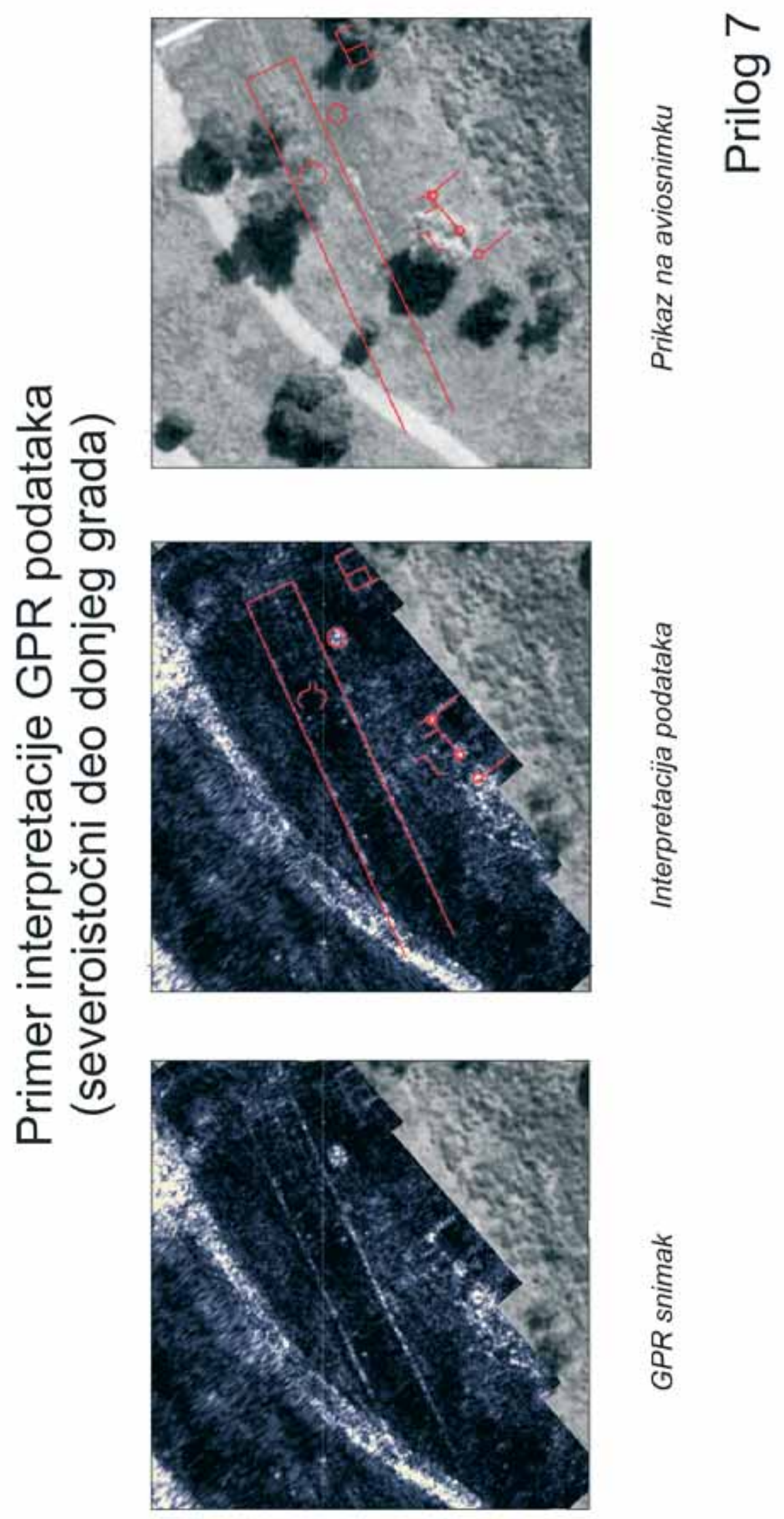




\section{Primer interpretacije GPR podataka (Gornji grad)}

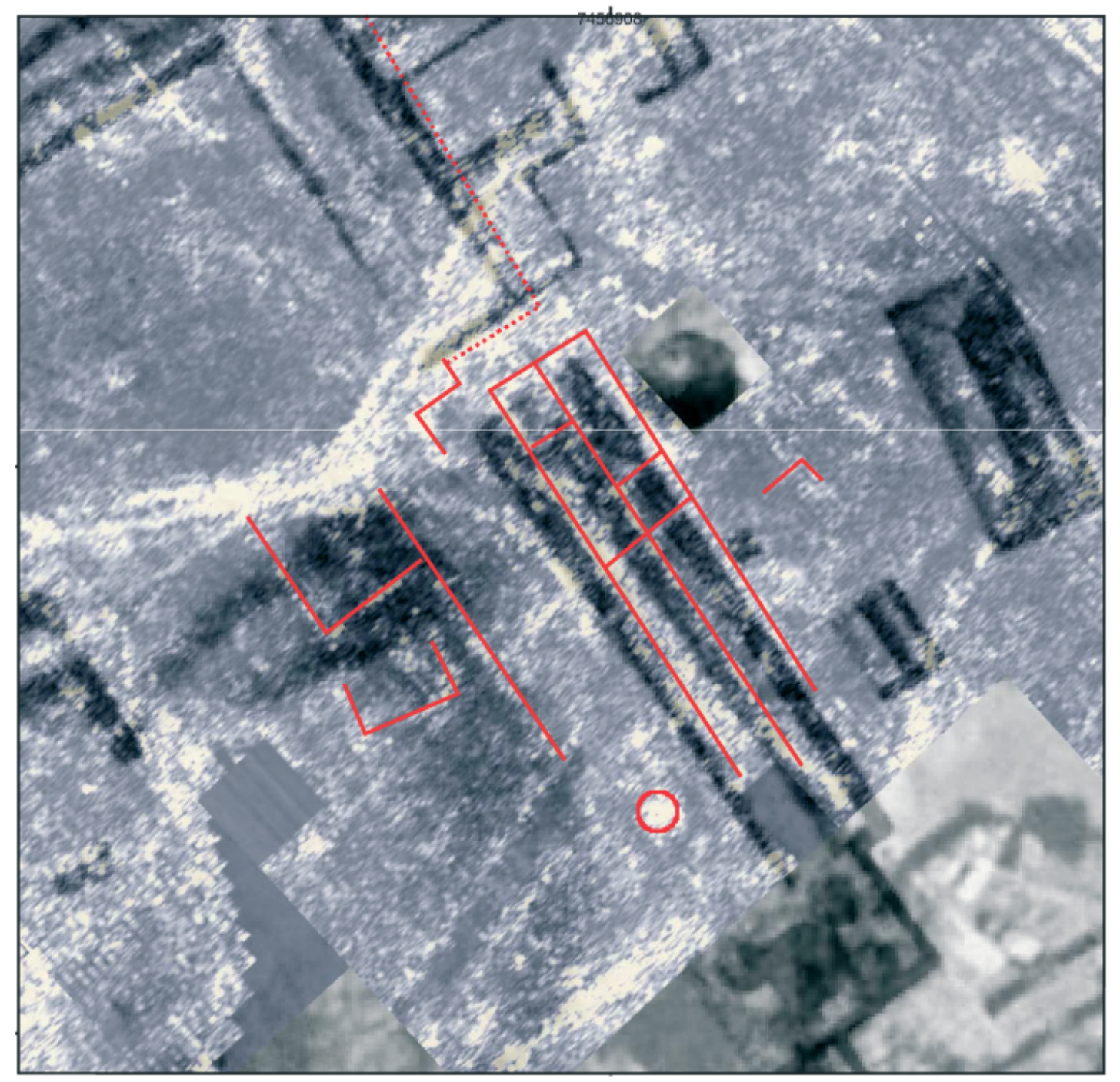

Poređenje rezultata dobijenih interpretacijom georadarskih podataka sa georeferenciranim planom Beogradske tvrđave iz 1790. God.

\section{Prilog 8}




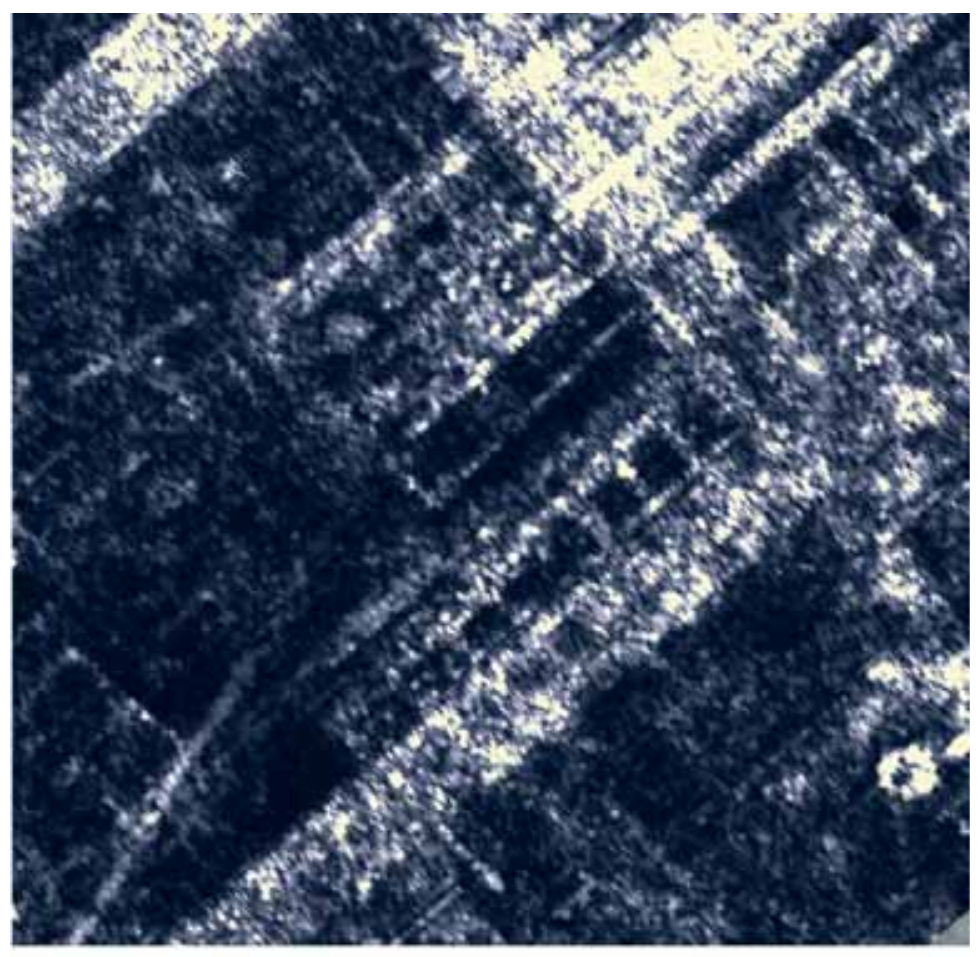

GPR istraživanja iz 2006. godine

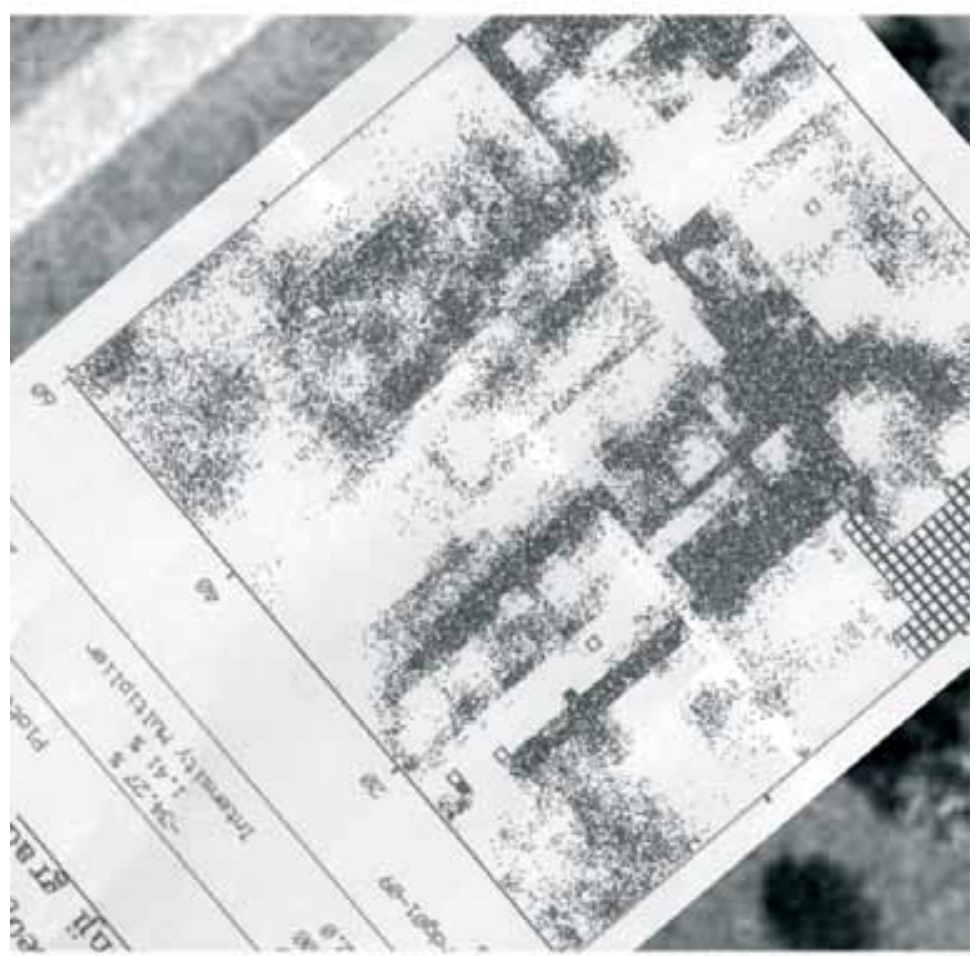

Geoelektrična Istraživanja iz 1990. godine

Prilog 9 


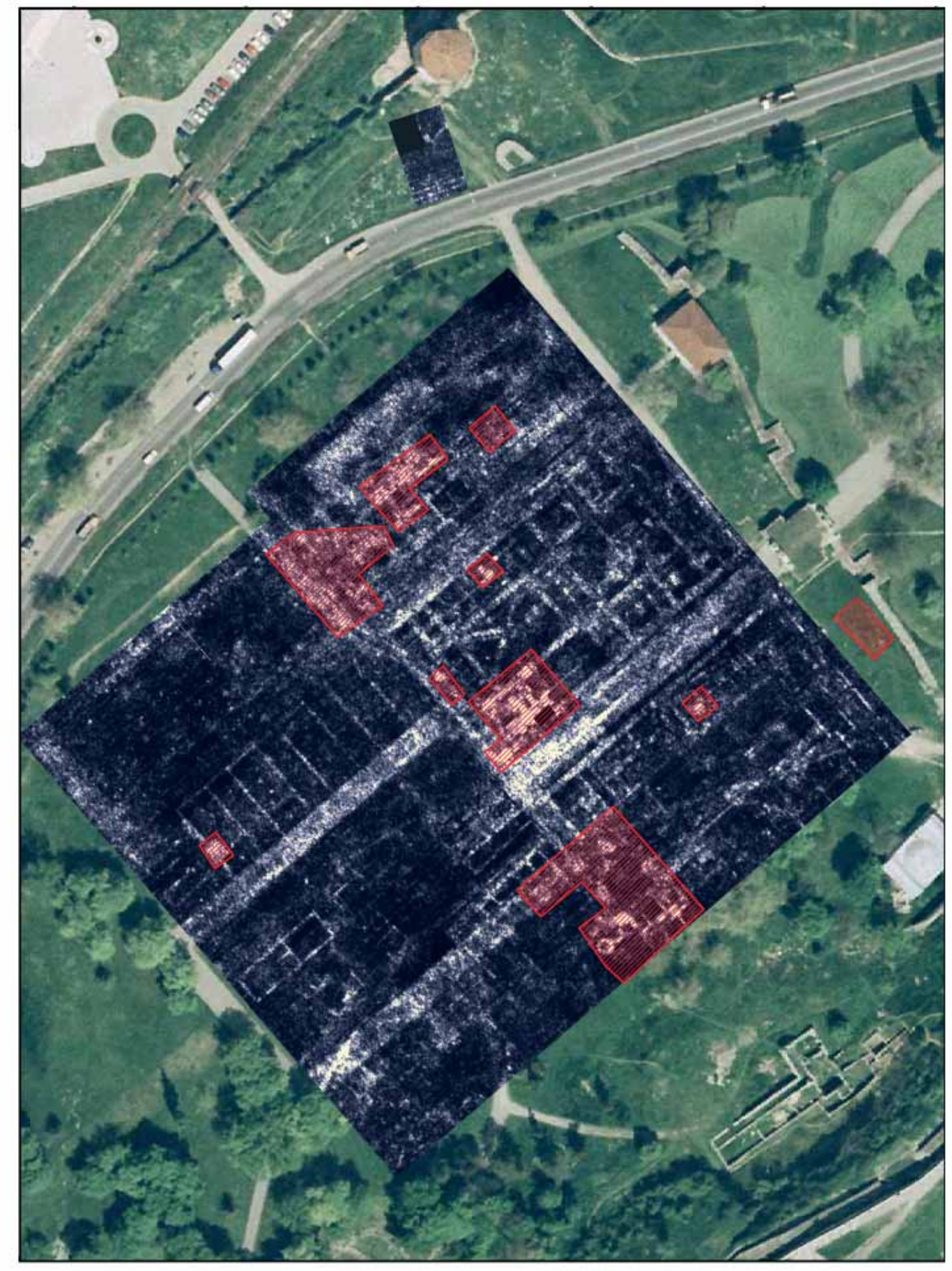

A $\quad$ Zone gde se mogu očekivati šupljine ili nekonsolidovan materijal ispod površine tla $1: 1,500$ Prilog 10 


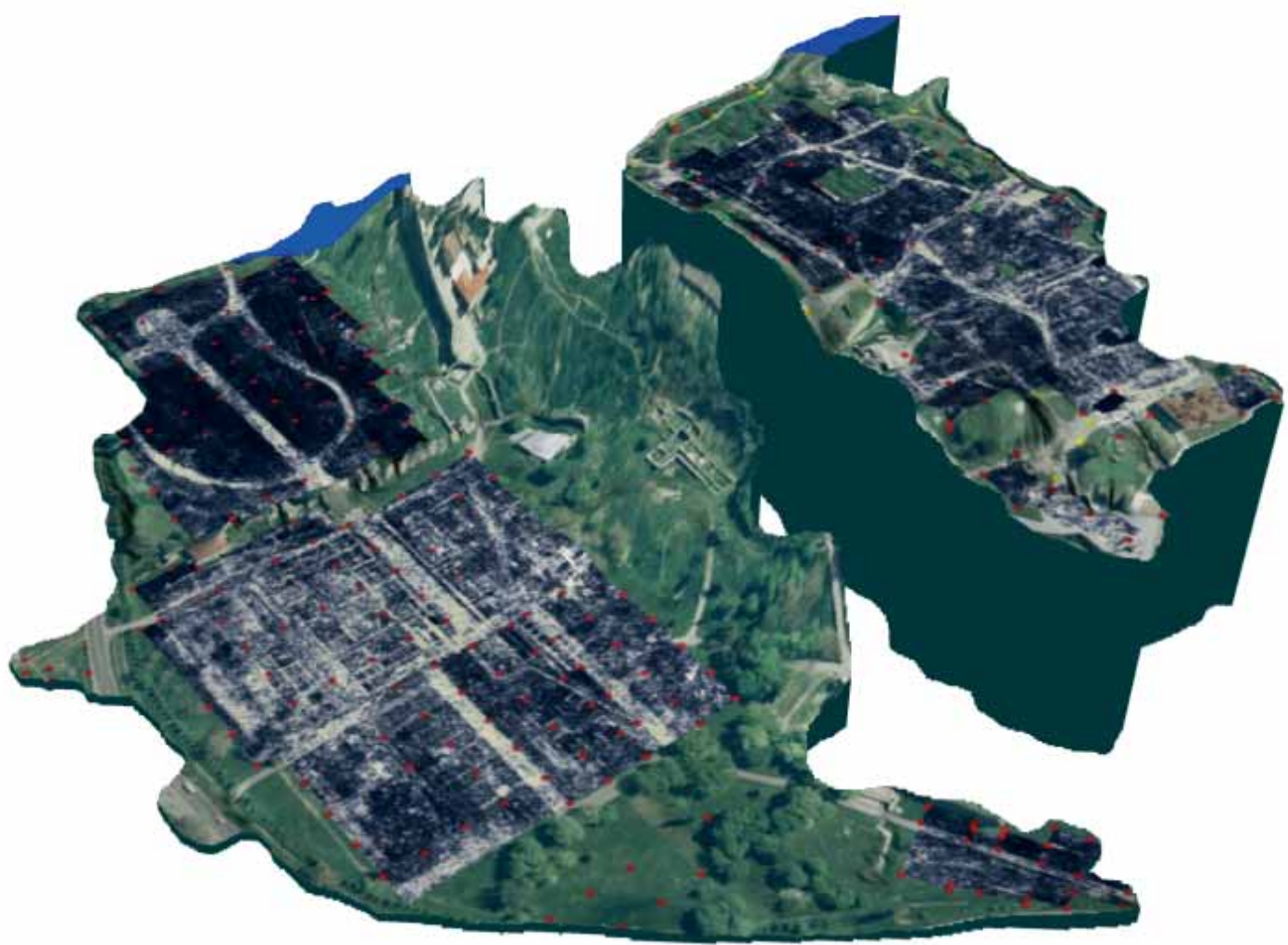

Kombinovanje digitalnog modela terena i rezultata geofizičkih istraživanja

\section{Prilog 11}

